\title{
Scaffolding our systems? Patients and families 'reaching in' as a source of healthcare resilience.
}

\author{
Jane K O'Hara, ${ }^{1,2}$ Karina Aase, ${ }^{3}$ Justin Waring ${ }^{4}$
}

${ }^{1}$ Leeds Institute of Medical Education, University of Leeds, Leeds, UK

${ }^{2}$ Yorkshire Quality and Safety Research Group, Bradford Institute of Health Research, Bradford Teaching Hospitals NHS Trust, Bradford, UK ${ }^{3}$ Faculty of Health Sciences, Centre for Resilience in Healthcare, University of Stavanger, Stavanger, Norway ${ }^{4}$ Centre for Health Innovation Leadership and Learning. University of Nottingham Nottingham, UK

\section{Correspondence to} Dr Jane K O'Hara, Leeds Institute of Medical Education, University of Leeds, Leeds LS2 9JT, UK;

jane.o'hara@bthft.nhs.uk

Accepted 16 April 2018 Published Online First 15 May 2018

\section{SLinked}

- http://dx.doi.org/10.1136/ bmjqs-2017-007292

Check for updates

To cite: O'Hara JK, Aase K, Waring J. BMJ Qual Saf 2019:28:3-6.
Redley and colleagues' study ${ }^{1}$ suggests that involving patients in their care can be challenging, even when patients express a preference for involvement. Their paper examines a key opportunity for patient engagement- the ward round-and investigates the links between patients' expressed preference to be involved and their observed level of involvement during subsequent ward rounds. The authors report little relationship between the two, concluding that involvement is affected by a range of contextual factors.

This finding, while disappointing, comes as little surprise to those who have spent any time in the ever-changing clinical environment of an acute hospital ward. What patients want in terms of active involvement, and what they can and do receive, varies in all kinds of ways. The reality of involving patients and families is that both preferences and opportunities for involvement are situated within a complex, dynamic healthcare system. Furthermore, it could be argued that by focusing only on a single opportunity for involvement-in this case shared decision-making within the ward round-we fail to recognise the role of patients and families as active partners across their care experience and the actions and adjustments they routinely make to support the quality and safety of their care. Put simply, these adjustments represent a source of resilience in our healthcare systems. In this editorial, we explore how facilitating these adjustments across the range of care experiences might create better quality and safer care.

\section{WHAT IS SYSTEM RESILIENCE, AND WHY SHOULD WE SEEK TO ENHANCE IT?}

Healthcare is increasingly recognised as a 'complex adaptive system', ${ }^{2-5}$ within which resilience is seen as:
... the intrinsic ability of a system to adjust its functioning prior to, during or following changes/disturbances in order to sustain required operations under expected or unexpected conditions. ${ }^{6}$

Thus, resilience is an attribute of a system that allows it to flex and adapt to unpredictable circumstances. Traditionally, such flexing has been seen in negative terms, described variously as 'violations' or 'work-arounds'. ${ }^{7}$ However, this flexibility may be what is needed to allow care delivery to meet the needs of varying conditions, to produce positive outcomes, and importantly, to support more patient-centred care. ${ }^{89}$

It has been suggested that the main solution for supporting resilience is to manage, or 'dampen' performance variability, particularly where variability may have a disproportionate impact on desired outcomes. ${ }^{10}$ We believe that patients, their families and carers, due to their unique positioning outside, inside and across healthcare system boundaries, are well-placed to provide this dampening function, and in doing so, may help to create better quality, safer care, more of the time.

\section{HOW MIGHT PATIENTS AND THEIR FAMILIES BE A SOURCE OF HEALTHCARE RESILIENCE?}

Consider for a moment the experiences when you, your family or friends, have sought care from health services. It is conceivable that you have had to undertake unexpected activity to achieve your goals. Examples might include chasing appointment times, or correcting the information on which clinical decisions are made. This type of activity may be understood as 'reaching in' to services and compensating for system complexity, and it is often necessary to achieve more 
optimal care. 'Reaching in' has the effect over time of creating a 'scaffold', supporting the ongoing work of healthcare professionals providing care. An emergent literature suggests that patients and families are already 'scaffolding' the quality and safety of their care, for example, undertaking their own reconciliation of their medications following discharge from hospital, or proactively contacting their GP or community pharmacy where medications have been changed. ${ }^{11}$ These kinds of activities, which might traditionally be seen as non-adherent, might actually be regarded as 'resilience strategies'. ${ }^{12}$

Traditionally, patient involvement has focused on discrete activities, such as 'speaking up' about hand washing, or exploring involvement at certain healthcare encounters, like the hospital ward round. ${ }^{1}$ However, it is our contention that going forward, we should seek to understand the ways that patients and families might be involved over time to help manage the inconsistencies and unwanted variability in the care system. To really support patients and families to be in a position to more systematically 'reach in' and to enhance resilience, we believe a shift in thinking and approach is necessary.

\section{HOW MIGHT WE FACILITATE PATIENTS AND FAMILIES TO ENHANCE HEALTHCARE RESILIENCE?}

\section{Provide opportunities for 'reaching in' to healthcare systems}

No health service can honestly claim to be built in the image of patient need or around the patient 'journey'. However, patients and their families may still regard health services as unified providers of care that share information and whose day-to-day interests align around the same focal point-provision of patient care. Thus, there may be a degree of naiveté among those using health services about the structural gaps that can lead to 'safety gaps' between services, staff, structures and settings. This disconnect is further complicated in times of high resource use (eg, 'winter pressures'), or during periods of sustained enforced efficiency savings, where the perception of what health services could and should deliver may fall short of the reality. When patients and their carers are aware of these issues, they may be enabled to think pre-emptively and proactively about the opportunities they might have in supporting the care process.

What is needed is to provide everyday opportunities for 'reaching in' to healthcare systems. Following on from known examples of resilient strategies, ${ }^{11} 12$ this could be as simple as an instruction at discharge from hospital: 'when you get home, you may wish to contact your GP and provide a copy of your discharge letter'. Or it may involve providing pathways that offer more systematic ways for patients, families and carers to 'interrogate' the healthcare system, through structured questions they may like to ask, explicit patient-centred instructions about treatment and medication or sharing information about signs and symptoms that need to be escalated quickly. Indeed, such a view is supported by findings from Redley and colleagues' study, ${ }^{1}$ where patients who indicated receiving information delivered in a way they could understand, as well as feeling respected and supported by clinicians, felt more able to meaningfully contribute to ward rounds.

\section{Acknowledge patients and families as knowledge brokers}

A related benefit of greater transparency about 'safety gaps' in our care systems is the potential for patients and families to act as 'knowledge brokers'. ${ }^{13}$ Knowledge brokers fill 'structural holes' between otherwise interconnected parts of a network. ${ }^{14}$ Patients and families have unique insight and tacit knowledge that can support safe progression through our imperfect healthcare systems. For example, their movement across and between system boundaries means that they are uniquely positioned to understand how different system components work, often in ways that eludes the understanding of professionals working within these component departments, wards or hospitals. This means that patients and their families are often able to support more timely information exchange across these gaps. An obvious example of this is emergency care, where in the absence of access to records, patients or their carers can become the main source of safety critical information for staff about medical history, treatment regimens and medication. ${ }^{15}$ Another aspect of the 'knowledge broker' role for patients and families might be providing a mechanism for information exchange between healthcare professionals. Existing examples of this are the successful use of personal child health records in maternity services ${ }^{16}$ and initiatives within care homes designed to provide important clinical information quickly on admission to acute services. ${ }^{17}$

\section{Coproduce interventions to allow variability}

Over the past decade, there has been a proliferation of interventions designed to support patient and family involvement in the quality and safety of care. However, the process of developing, testing and spreading interventions to improve healthcare is undergoing what might be regarded as a small paradigm shift, with an increasing number of authors calling for a rethink about how to create change. ${ }^{18-21}$ Collectively, this critique suggests that rather than seeking to tightly control interventions to ensure uptake and spread, we create 'hybrid' interventions where some aspects are more prescribed, with others left free to vary depending on local contexts. ${ }^{18} 19$ This approach aligns with complexity science, resilience approaches, as well as current thinking about creating safety within healthcare. ${ }^{22}$ But how does this relate to enabling patients and their families to enhance resilience? 
Activities that have significant variation, and that are closely connected with other variable activities, are likely to be key targets for improvement as they may have disproportionate 'knock forward' benefits on patients' outcomes, safety and experience. ${ }^{23}$ It may be that certain key-perhaps more 'upstream'-activities within healthcare processes should be more prescribed, leaving other activities-perhaps those 'downstream'-to vary according to context. An example of one such 'hybrid' intervention is arguably the New Medicine Service, which asks community pharmacists to support patients with medication adherence. ${ }^{24}$ The initial intervention point is prescribed with an interview schedule, but subsequent follow-up varies dependent on the outcomes of the early conversations and patient need. ${ }^{24}$ From the patient perspective, such a hybrid intervention might be a prescribed set of key questions patients and families could ask when being discharged from hospital, allowing better informed (but variable) discussions to take place with different healthcare professionals across community and primary care services once home. In a sense, such an approach would be akin to asking patients and families to be partners in healthcare, sharing a responsibility to 'co-produce' the quality and safety of their care. ${ }^{25}$

\section{CONCLUSION}

Trying to understand and work with complexity in healthcare systems is inherently a complex endeavour. Patients and families have long been seen as a source of unwanted variability in treatment outcomes (eg, medication adherence), but patients and families may also be a unique source of insight and resilience in supporting the quality and safety of our healthcare processes. The key to harnessing this role more fully is likely to include moving away from a focus on specific patient and family involvement in specific aspects of care delivery, like the ward round. ${ }^{1}$ We argue that for healthcare to fully benefit from this resilience capacity requires us to let go of traditional beliefs about tightly controlling interventions, allow staff to continue to flex and adapt to changing conditions and craft 'gentle scaffolds' to allow patients, families and carers to better interrogate, navigate and thrive in the sometimes intricate maze of healthcare services.

\section{Acknowledgements JKO would like to extend her thanks to colleagues within the Yorkshire Quality \& Safety Research Group, in particular Jenni Murray, Ruth Baxter, Natasha Hardicre and Rebecca Lawton, whose conversation has supported the development of these ideas.}

Contributors JKO conceived the idea for the article and drafted the manuscript. KA and JW provided comments, input and revisions. All authors agreed the final version prior to publication.

Funding This article is informed by independent research funded by the National Institute for Health Research (National Institute for Health Research Programme Grants for Applied Health Research, Partners at Care Transitions (PACT): Improving patient experience and safety at transitions in care,
RP-PG-1214-20017) and supported by the National Institute for Health Research Yorkshire and Humber Patient Safety Translational Research Centre (NIHR Yorkshire and Humber PSTRC).

Disclaimer The views expressed in this publication are those of the authors and not necessarily those of the NHS, the National Institute for Health Research or the Department of Health and Social Care.

Competing interests None declared.

Patient consent Not required.

Provenance and peer review Commissioned; internally peer reviewed.

(C) Article author(s) (or their employer(s) unless otherwise stated in the text of the article) 2019. All rights reserved. No commercial use is permitted unless otherwise expressly granted.

\section{REFERENCES}

1 Redley B, McTier L, Botti M. Patient participation in inpatient ward rounds on acute inpatient medical wards: a descriptive study. BMJ Qual Saf 2019;28:15-23.

2 Kannampallil TG, Schauer GF, Cohen T, et al. Considering complexity in healthcare systems. J Biomed Inform 2011;44:943-7.

3 Braithwaite J, Wears RL, Hollnagel E. Resilient health care: turning patient safety on its head. Int J Qual Health Care 2015;27:418-20.

4 Wears RL, Hollnagel E, Braithwaite J. Resilient Health Care Volume 2: The Resilience of Everyday Clinical Work. Farnham, UK: Ashgate Publishing Limited, 2015.

5 Hollnagel E, Braithwaite J, Wears RL, et al. Resilient health care. Farnham, UK: Ashgate Publishing Limited, 2013.

6 Hollnagel E. Making health care resilient: From Safety-I to Safety II. In: Hollnagel E, Braithwaite J, Wears RL, eds. Resilient healthcare. Farnham, UK: Ashgate Publishing Limited, 2013.

7 Hollnagel E, Wears RL, Braithwaite J. From Safety-I to Safety-II: A White Paper. Denmark: The Resilient Health Care Net. Published simultaneously by the University of Southern Denmark, University of Florida, USA, and Macquarie University, Australia.

8 Aase K, Waring J, Schibevaag L. Researching quality in care transitions: international perspectives. Switzerland: Palgrave Macmillan, 2017.

9 Waring J, Marshall F, Bishop S, et al. An ethnographic study of knowledge sharing across the boundaries between care processes, services and organisations: the contributions to 'safe' hospital discharge. Health Services and Delivery Research 2014;2:1-160. ISSN 2050-4349.

10 Hollnagel E. FRAM: The functional resonance analysis method. Boca Raton, USA: CRC Press, 2012.

11 Fylan B, Armitage G, Naylor D, et al. A qualitative study of patient involvement in medicines management after hospital discharge: an under-recognised source of systems resilience. BMJ Qual Saf 2018;27:539-46.

12 Furniss D, Barber N, Lyons I, et al. Unintentional nonadherence: can a spoon full of resilience help the medicine go down? BMJ Qual Saf 2014;23:95-8.

13 Hargadon $\mathrm{AB}$. Brokering knowledge: linking learning and innovation. Res Organ Behav 2002;24:41-85.

14 Bishop S, Waring J. The knowledge brokering situations of care transitions. In: Aase K, Waring J, Schibevaag L, eds. Researching quality in care transitions: international perspectives. Switzerland: Palgrave Macmillan, 2017. 


\section{Editorial}

15 Storm M, Siemsen IM, Laugaland K, et al. Quality in transitional care of the elderly: Key challenges and relevant improvement measures. Int J Integr Care 2014;14:1-15.

16 RCPCH. Personal child health record. https://www.rcpch.ac. uk/personal-child-health-record (accessed 5th Mar 2018).

17 NICE. Hospital transfer pathway (Red Bag Pathway). https:// www.nice.org.uk/sharedlearning/hospital-transfer-pathway-redbag-pathway (accessed 5th Mar 2018).

18 Lilford RJ. Implementation science at the crossroads. BMJ Qual Saf 2018;27.

19 Hawe P. Lessons from complex interventions to improve health. Annu Rev Public Health 2015;36:307-23.

20 Shiell A, Hawe P, Gold L. Complex interventions or complex systems? Implications for health economic evaluation. BMJ 2008;336:1281-3.
21 May CR, Johnson M, Finch T. Implementation, context and complexity. Imp Sci 2016;11:141.

22 Vincent C, Amalberti R. Safer healthcare: strategies for the real world. New York, NY: Springer Open, 2016. ISBN: 9783319255576.

23 Entwistle VA, Watt IS. Patient involvement in treatment decision-making: the case for a broader conceptual framework. Patient Educ Couns 2006;63:268-78.

24 Elliott RA, Boyd MJ, Salema NE, et al. Supporting adherence for people starting a new medication for a long-term condition through community pharmacies: a pragmatic randomised controlled trial of the New Medicine Service. BMJ Qual Saf 2016;25:747-58.

25 Rhodes P, McDonald R, Campbell S, et al. Sensemaking and the co-production of safety: a qualitative study of primary medical care patients. Sociol Health Illn 2016;38:270-85. 